Paper ID \#17830

\title{
From graduate students to faculty: portraits of balance in the professional development plans of engineering graduate students
}

\author{
Mr. Juan David Ortega-Alvarez P.E., Purdue University, West Lafayette / Universidad EAFIT, Medellin, \\ Colombia
}

Juan David Ortega Álvarez is an assistant professor at Universidad EAFIT (Medellin, Colombia). He holds a bachelor's degree in Process Engineering from EAFIT and an M.S. in Process Engineering and Energy Technology from Hochschule Bremerhaven (Germany). Juan David is currently a third-year doctoral student of the Engineering Education Program at Purdue University. Before his full-time appointment with EAFIT, he served as the engineering director at a Colombian chemical company for seven years. His research interests are focused on the practice and teaching of process design, simulation and control, and also on faculty and institutional development through educational research.

\section{Dr. Ruth A. Streveler, Purdue University, West Lafayette (College of Engineering)}

Ruth A. Streveler is an Associate Professor in the School of Engineering Education at Purdue University. Dr. Streveler has been the Principal Investigator or co-Principal Investigator of ten grants funded by the US National Science Foundation. She has published articles in the Journal of Engineering Education and the International Journal of Engineering Education and has contributed to the Cambridge Handbook of Engineering Education Research. She has presented workshops to over 500 engineering faculty on four continents. Dr. Streveler's primary research interests are investigating students' understanding of difficult concepts in engineering science and helping engineering faculty conduct rigorous research in engineering education. In 2015, Dr. Streveler was inducted as an ASEE Fellow.

Dr. Audeen W. Fentiman, Purdue University, West Lafayette (College of Engineering)

Audeen Fentiman is Associate Dean of Engineering for Graduate Education and Interdsiciplinary Programs and the Crowley Family Professor in Engineering Education at Purdue University.

Mr. Harsh Wardhan Aggarwal, Purdue University

Graduate Research Assistant, Purdue University

Mr. Sayan Biswas, School of Aeronautics and Astronautics, Purdue University

Sayan Biswas is a PhD student in the department of Aeronautics and Astronautics Engineering, Purdue University. His research interest is rocket propulsion and computational fluid dynamics of reacting flows. $\mathrm{He}$ is also interested in different educational methods in aerospace engineering. Sayan teaches rocket propulsion, air breathing propulsion, and fluid mechanics. Other than teaching, Sayan like launching model rockets and flying airplane.

Mr. Brandon S Coventry, Weldon School of Biomedical Engineering, Purdue University; Institute for Integrative Neuroscience, Purdue University

Brandon received his bachelors degree in electrical engineering from Saint Louis University in 2012 and his masters in electrical and computer engineering from Purdue University in 2014. He is currently a PhD student in biomedical engineering at Purdue University under the guidance of Edward Bartlett, PhD. His research interests include optical neural stimulation, computational and systems neuroscience, and novel neural engineering technologies.

Abdel-Rahman Hassan, Purdue University, West Lafayette (College of Engineering)

Abdel-Rahman Hassan is a PhD candidate at the Weldon School of Biomedical Engineering, Purdue University. Abdel-Rahman obtained his bachelor's degree in Nuclear Engineering at Alexandria University, Egypt. He has a master's degree in Materials Science and Engineering from Florida State University. Currently, Abdel-Rahman conducts research in biomechanics of cell migration. Abdel-Rahman has interest in multidisciplinary research especially using theoretical and computational techniques. Recently, he developed an interest in engineering education within the biomedical field and in how to bring the benefits of theory and mathematical analysis to such audience. 


\section{Margaret L. McNamara, Purdue University}

Margaret McNamara is a third year PhD student in civil engineering with a focus on transportation at Purdue University. Her research is in leveraging new data sources for interstate performance monitoring. She received her Bachelor's and Master's degrees in civil engineering from the University of Virginia.

\section{Mr. SMRITI NANDAN PAUL, PURDUE UNIVERSITY}

Smriti Nandan Paul is currently pursuing his PhD at School of Aeronautics and Astronautics, Purdue University under the advice of Dr. Carolin Frueh. 


\title{
From graduate students to faculty: portraits of balance in the professional development plans of engineering graduate students
}

\begin{abstract}
The job of a college engineering faculty member is multifaceted. Faculty are not only expected to teach and conduct research but also to write proposals, consult, network, engage in administrative duties, and the list continues. The relative importance and time allocated to these different functions vary according to the nature and focus of the institution and the interests of the faculty. However, engineering graduate students aspiring to careers in academe are not usually trained in the multiple facets of the profession. As a result, when they become faculty members they often struggle to find ways to balance the parallel and many times competing demands of these functions.

This paper examines the professional development plans of six engineering graduate students with a marked interest in an academic career. These plans are one of the major deliverables of a three-credit graduate course at a large, research-intensive university. The overarching goal of this course, as stated on its syllabus, is to provide students with an opportunity to learn and practice the skills that complement and enhance classroom teaching and learning in a tenure-track faculty position, either at a research-intensive university or at an institution that focuses on undergraduate engineering education. The research questions that orientate the study are: What do the professional development plans of engineering graduate students portray about their striving for balance in their future faculty careers? How does writing a professional development plan with expert guidance in a formal class help these students prepare for a faculty position?

The analysis of students' professional development plans as qualitative artifacts, under the lens of expectations and values, reveals a wide variety of approaches to the role of faculty. Subsequent individual reflection on these plans allowed researchers to gather insights into why students chose to focus on different perspectives of the faculty job. Finally, a follow-up group conversation with the students shows that beneath these different perceptions and expectations lies the idea of balance, evolved and transformed by the discussions and activities of the course.
\end{abstract}

\section{Introduction}

The literature on the experiences of early-career faculty careers provides evidence of the stress and struggles they face to cope with the multiple demands of the academic, professional setting ${ }^{1}$. These difficulties become more pronounced if personal expectations and interests deviate from the traditional requirements of a tenure-track position ${ }^{2}$. Recurring themes among these difficulties include: 1) balancing the competing demands of research, teaching, and other professional and personal duties; 2) lack of time to cope with all responsibilities; and 3) setting realistic expectations, particularly regarding research and publication accomplishments ${ }^{1,3,4}$. Emphasizing the first theme, Felder and Brent point out that a remarkably difficult challenge is finding out a way to "balance the competing time demands of teaching, research, and other professional and personal responsibilities”3. In that vein, this paper focuses on exploring notions of balance.

The past two decades have seen the appearance of various institutional- and national-level initiatives to help junior engineering faculty deal with the difficulties mentioned above and successfully commence 
their careers. Usually, these initiatives take the form of courses and workshops adapted to the specific context of every institution ${ }^{3,4}$. Sometimes, they take the form of guidelines providing tips and "tricks of the trade” drawn from literature and the experience of successful faculty 5 .

The early 1990s also witnessed the strengthening of programs aimed at better preparing doctoral students for future faculty positions. Among other things, these programs considered the inclusion of faculty professional development and the so-called 'soft skills' as a formal part of the doctoral training . Similarly, in the past decade, academic consortiums and national offices have supported the creation of programs aimed at training doctoral students in STEM disciplines, mostly for future teaching duties. Although such programs contribute to preparing students to assume academic or other professional positions, their ultimate goal is to improve the quality of undergraduate education ${ }^{7}$.

Some scholars have considered, designed, and documented initiatives that target engineering graduate students to help them successfully transition into faculty careers. Drawing from the general programs started in the 90s, such initiatives comprise formal courses and professional development workshops, and rely to a great extent on mentorship ${ }^{3}$. More recently, institutional initiatives have been specifically tailored to engineering education graduate students; namely, an internship program comprising a semester-long experience based on an a apprenticeship model ${ }^{8}$.

Most of the initiatives above have been documented from the perspective of their design underpinnings, expected outcomes, and benefits perceived by designers and instructors. In contrast, our study intends to add to this panorama the firsthand perspective of engineering graduate students interested in an academic career. Particularly, we look at the experience of six graduate students from different engineering disciplines as they transit a 3-credit, semester-long course aimed at preparing them for future faculty positions. The name of this course is Succeeding as an Engineering Professor (SEP), and its main goal is to offer students the opportunity to look at and exercise in multiple facets of the faculty job. In addition, it aims at making students aware of the variety of positions available in the academic job market.

The aim of this paper is twofold: we intend to explore 1) graduate students' expectations, interests, and assumptions about their future faculty lives, and 2) the usefulness of the SEP course, as the students perceive it, in helping them prepare for a future faculty position. As stated before, the exploration of students' perceptions is focused on the notion of balance. Consequently, the research questions that orientate the study are: 1) what do the professional development plans of engineering graduate students portray about their striving for balance in their future faculty careers? And 2) how does writing a professional development plan with expert guidance in a formal class help these students prepare for a faculty position?

\section{Research Design}

\section{Theoretical framework}

The students in the SEP class come from diverse cultural and disciplinary backgrounds, but they all have something in common: the motivation to pursue a career in academia as faculty members. Such motivation constitutes the common ground explored in search of different approaches to a balanced faculty life. Among the multiple frameworks available to explore motivation and decision-making in academic settings, Eccles' Expectancy-Value Theory was chosen to inform the data collection and make sense of the findings. Various studies of decision-making in engineering education have relied on this theory as a suitable theoretical framework, including studies by some authors of the present paper ${ }^{10,11}$. 
This framework was selected because of its suitability for looking at the underlying assumptions and beliefs that motivate people to engage in a task in academic contexts. According to the Expectancy-Value Theory, two factors motivate one's decision to engage in a task: 1) the self-belief in one's ability to accomplish the task, and 2) one's willingness to engage in the task ${ }^{9}$.

The willingness to engage in a task can be further classified into what Eccles has defined as subjective task values (STV). There are four categories of STV in Eccles' theory: 1) attainment, 2) intrinsic, 3) utility, and 4) relative cost. Attainment value is defined as the reflection of one's perception of a task on one's self-concept. Intrinsic or interest value is related to the enjoyment one experiences when engaging in a task. Utility value is defined as a perception one has of the potential outcomes of future engagement in a particular task. Finally, the relative cost is the cost of engaging in a task in terms of time, effort or psychological factors associated with it ${ }^{9,12}$.

\section{Participants and data collection}

The participants in this study, who are co-authors of this paper, are one female and five male engineering Ph.D. students, registered in the class Succeeding as an Engineering Professor offered at a large, research-intensive Midwestern university in the Fall of 2016. Two of them are domestic students, and the other four are international students, all of them considering an academic career in the United States. They are all past the second year in their respective programs, namely aeronautics and aerospace, biomedical, civil, and industrial engineering.

During the first three weeks of the class, the students were required to write a professional development plan (PDP) to become proficient for a faculty position at an institution of their choice. The instructor facilitated students' writing of the PDP through class discussions about the different responsibilities of engineering faculty and the variety of positions available according to the types and aims of different institutions. Additionally, she provided handouts listing and describing faculty functions beyond the wellknown research, teaching, and service (e.g., mentoring, networking, and so forth). The instructor encouraged students to write their PDPs considering these materials, while also drawing upon their experiences and personal interests.

At the end of the semester, after completing all activities in the SEP class, students were asked to revisit the first draft of their PDP from a reflective stance. Given their dissimilar experience with systematic reflection, the first author provided a short reading to guide the reflective exercise ${ }^{13}$. Similarly, he provided a simplified description of Eccles' framework, relating values to students' interests and expectations to the confidence in their future performance of the different faculty functions. The following prompts were presented to the students to help orientate and bound the content of their reflections:

When writing the professional development plan for the first time,

- Why did you want to develop/involve in some faculty functions (e.g., teaching, research, service, etc.)?

- Are there faculty functions you deliberately decided not to develop/involve in, or do it in a more moderate manner? If yes, why is that the case?

- What were your beliefs regarding your ability to accomplish the different roles of an engineering faculty member? 
The first two questions aimed at eliciting assumptions and value beliefs, whereas the third one was intended to explore expectations and competence beliefs. The students wrote their individual reflections over two weeks after receiving these questions and the guiding reading. Once all the individual reflections were collected, the first author and the participants engaged in a group conversation using a variation of the fishbowl technique ${ }^{14}$. The fishbowl conversation was set up so the participants formed a circle around two chairs reserved for the moderator and one interlocutor. The first author assumed the role of the moderator and invited a volunteer to become the first interlocutor. The moderator prompted interlocutors to elaborate on the insights of their reflections related to the research questions of the study. Whenever a participant in the circle felt they had something to contribute about a topic being discussed, they tagged the interlocutor in the fishbowl and became the new interlocutor. The participants were acquainted with the technique before starting the conversation. During the conversation, the moderator made sure that every participant had at least one turn in the fishbowl and equitable time for talking. The conversation lasted around 40 minutes and was audio recorded. After the fishbowl, students were encouraged to complement their written reflections with new insights arisen from the collective dialogue. These final reflections and the recorded conversation constitute the data for this study.

\section{Data analysis}

The analysis process comprised three main stages. In the first round of analysis, the first author looked at each reflection and extracted themes related to values, expectations, and the underlying assumptions. As discussed before, values were operationalized as explicit interests and expectations as statements regarding confidence, or lack thereof, to perform specific faculty functions. Aiming for trustworthiness, each participant was individually debriefed for member-checking after the first round of analysis. In the second round of analysis, themes extracted from the reflections where triangulated and refined with insights from the fishbowl conversation transcript using thematic coding in Nvivo 11.4. The themes driving the coding process were subcategories of values (e.g., interest in doing research), expectations (e.g., confidence in teaching skills), and assumptions (e.g., a faculty job comprises just teaching and research). At the end of the second round of analysis, the experienced faculty coauthors discussed with the first author the analysis and findings. This discussion yielded the final version of the results, presented in the next section.

The participants who are also coauthors of this paper were tasked with writing their PDP and the subsequent reflections on them. Except for member-checking purposes, only the first author and the experienced faculty coauthors participated in the analysis phase. The first author, who was a student in the SEP class along with the participants, is an international Ph.D. student of engineering education in the United States. He was a full-time engineering faculty member in his home country for five years, now on a leave for doctoral studies. His experience, thus, better resembles that of a junior professor rather than that of a graduate student aspiring to a faculty position. For these reasons, he is not a participant in the study although he fully engaged in the activities of the SEP class. Instead of contributing data to the study, he used his experience as both an engineering education researcher and a class participant to collect and analyze the data. The experienced faculty coauthors looked for consistency in the resulting thematic schemes, and helped the first author refine the final version and check for alignment with the research questions. The first author acknowledges that his experience as a faculty member might have influenced the analysis process. In order to minimize this potential influence, the collection and analysis instruments were grounded in theory and in the recurring themes found in literature. 


\section{Results}

Research Question 1: Striving for balance in a faculty career as reflected by the PDP

The reflections and dialogues elicited common themes that reveal implicit tactics aimed at achieving a successful and balanced faculty career. Among these themes, three were prominent: 1) Balancing skills with requirements, 2) balancing teaching and research, and 3) pursuing intrinsic, interest, and attainment values. These themes are not sharply delineated; instead, they are intertwined and feed into each other. In addition, mentoring appeared as a loosely related yet clearly distinguishable fourth theme.

\section{Balancing skills with requirements}

Most students viewed the PDP as an opportunity to identify their strengths and weaknesses in light of their understanding of the faculty functions, and aimed for improvement in the weak areas. Different paths in graduate school result in students having different levels of expertise in the functions of faculty, mostly teaching and research. In turn, they considered actions they could take to address the gap between their skills and the requirements of a faculty position as they conceive of it. At the beginning of the class, such preconceptions of job requirements were partially complete or inaccurate.

"There are three main things which are valued, right? Teaching... Research, teaching, and service, so I had the other two. It's just the research part which I felt was weak and I wanted to spend more time towards that."

Harsh (fishbowl)

"My plan largely focuses on identifying weaknesses and gaps in my understanding, but lacks actionable methods to address them."

Maggie (reflection)

Besides identifying weaknesses, the last quote from Maggie also points to the specific support that could be provided to graduate students to prepare them better for faculty positions. This point will be revisited and expanded in the discussion of the second research question. Sticking with the first theme, an important distinction was identified: students' decision to strengthening weak areas is not necessarily aligned with their interest values. In some cases, this decision responds mainly to utility values. In other words, students will engage in tasks they deem useful or necessary for their careers, even if they are not particularly thrilled about them. For instance, Brandon provided a hint of alignment between interest and utility values when he commented the following during the fishbowl:

"Because I am looking at a research-focused career, I tended to play higher emphasis on what I thought were more salient features of research [...] So I primarily focused on skillsets that I thought were very important to the research aspect of my career, but that I was particularly not great at."

Brandon (fishbowl)

On the other hand, from a utility value-driven approach, Paul focused on job requirements when writing his plan and Harsh added the following when asked about his interest in reinforcing his research skills:

"I put certain things here [in the PDP] that I need to improve, just so that I can be job-sellable as a professor." 
"When I wrote the development plan I didn't have that [interest in a particular research topic], so if you are asking why I wrote it [that I needed to develop research skills] is because I had to do it. And in this three months I have figured out what I want to do, so now I want to do it."

Harsh (fishbowl)

It is worth noting that sometimes the writing of the PDP allowed students to broaden their view of areas in which they feel confident to perform. As a result of this broader perspective, they decided to strive for improvement.

"The plan has emphasized care for aspects of teaching that are not necessarily addressed in the graduate student experience. This includes preparing a syllabus and designing a course material. [...] I have in consequence decided to ensure my qualifications-despite my experience-for teaching by registering in available courses of engineering education."

Hassan (reflection)

The previous quote by Hassan brings up another relevant issue: graduate students' conception of the teaching function. Most of the students in this study mentioned their interest in performing well as teachers. Moreover, they are confident in their teaching skills based on previous experiences as instructors or teaching assistants. However, they usually describe teaching from the perspective of understanding complex material, being able to present it in a clear fashion, and having an agreeable interaction with the students. Few participants mentioned course and syllabus design, pedagogical strategies, and other relevant aspects of the teaching function that usually go unnoticed to students.

2. Balancing teaching and research

More often than not, the discussion of motivation was centered on different notions of balance between the teaching and research activities. Most students addressed this idea in their plans from the perspective of their previous experience and interests. Whereas many students in this study felt they had experience in both activities, most of them seemed interested in performing more research than teaching, even if just slightly more.

"Research is the most attractive part that [inspires] me to be a faculty member. Besides research, I like teaching as well. I always like to explain my subject in easy fashion. I believe a good researcher should have total grasp over his/her subjects first.”

Sayan (reflection)

"As I want to pursue a research-based professorship, much of my attention was focused on skills which would facilitate that aspect of my career. [...] My document was more focused on research skills and only moderately involving teaching."

Brandon (reflection)

"With research, you are always up to creating something new. In teaching, you are not creating something new; you are creating a path to creating something new, you are... helping the students to get prepared for creating something new. You are not necessarily creating something new. And I am more interested in when you actively pursue something, or you create something, and that only happens through research." 
In describing both activities in relation to each other, Paul also revealed a hint of interest and intrinsic values. Sayan also focused on both activities and adventured a percentage of what balance between them looks like for him:

"I always kept research like a little higher priority [...] So that's why when I wrote the plan, I had $60 \%$ of research, $40 \%$ teaching, and some time for service, because the first few classes I understood that those are also important."

Sayan (fishbowl)

Without disclosing any inclination, Hassan reflected on the balance between teaching and research as a desirable characteristic of the faculty job. In fact, such characteristic fosters his interest to become a faculty member.

"The balance between teaching and research in a faculty's job is appealing for my purposes. Both aspects of the job feed into each other and help enhance the quality of either product."

Hassan (reflection)

The strategies to balance teaching and research can also be driven by utility values. For instance, Harsh has decided to focus on becoming a competitive candidate for a research-focused institution, as presented in the first theme.

"I want to do moderate work in teaching and focus more on research as I think I have enough teaching background to apply for a faculty position. [...] To be a successful candidate at an R-1 university, I need to have more publications..."

\section{Harsh (reflection)}

As will be shown in the presentation of the fourth theme, Harsh is intrinsically motivated towards teaching, possibly more than he is towards research. Still, he chose to devote more time and effort to develop research now, aiming at a referent of the faculty job that he conceives. It may be the case that other referents of the faculty job, perhaps those not coming from research-intensive institutions, could better leverage Harsh's intrinsic motivation.

\section{Pursuing intrinsic, interest, and attainment values}

Besides telling the stories behind the writing of the PDPSs and eliciting implicit assumptions, the initial reflections usually portrayed attainment and interest values. The group discussion sparked a deeper reflection, which moved some students to complement their initial write-ups with reflections on deeper intrinsic values. For instance, Hassan started his write-up with a couple of sentences regarding his general motivation:

"I have always had ambition to become a faculty member. The reason was my tendency to focus on theoretical aspects of science in service of progress. A faculty position is unique in that it offers a lot of freedom for researchers of that particular type regardless of industry requirements."

Hassan (reflection)

This quote evidences attainment and interest values motivating the decision to become a faculty member. Moreover, it presents an interesting assumption about the freedom faculty researchers have to choose their research topics. Similarly, Paul also referred to his motivation to becoming a faculty member in a fashion that mixes attainment and interest values. 
"Research and multi-tasking were my future goals, and being a professor seemed to be the only way to achieve those goals." "If you become professor, you can do a lot, intense multitasking. You can meet lots of people, you can gain lots of different experiences, different skillsets. But if you go to a lab you will just do research, no one will knowyou. [...] In the world of research, professors are like stars."

Paul (reflection + fishbowl)

From a perspective of intrinsic values, consistent with his primary interest on the research facet of his future professorship in the biomedical field, Brandon added the following idea to his reflection after the fishbowl conversation:

"I want to state that the reason I'm becoming a professor is my overall goal of being a servant to humanity and ease as much suffering as humanly possible."

Brandon (reflection)

In the same vein of intrinsic values, Harsh clearly stated one of the main reasons to become a faculty member:

"I love teaching. Teaching is one of the primary reasons I am a Ph.D. student and want to become a faculty member. [...] The amount of learning I get to do on the job is tremendous. Every single student who walks in my office or in my classroom is a chance for me to learn something new. [...] I get to teach students and the joy of changing someone's lives this way is very fulfilling for me. "

Harsh (reflection)

Sayan also discussed the intrinsic motivation propelling him to engage in academic tasks, namely research and teaching. The intrinsic motivation towards his research field, as presented in the second theme, is what inspires him to become a faculty member.

"I love solving complicated physical problems performing scientific experiments and theoretical analysis. Also, I love and care about my subject. Love for my subjects motivates me to teach in simple and easy manner. I feel when I teach, I inspire another generation of future propulsion and combustion engineers."

Sayan (reflection)

Following a different approach, Maggie realized that her motivation to becoming a faculty member was not clear to her when she started writing the PDP.

“That's actually the only reason that I'm doing a Ph.D. [to become a faculty member], what I've never examined was really why do I want to be a faculty member and what are the things that a faculty member does that are important to me."

Maggie (fishbowl)

However, although she recognized that her PDP did not portray her values in a clear manner, in her reflection she started eliciting those values. The next sentence begins to answer the question as to why she wants to become a faculty member.

"My values are very muddled throughout this document, largely a result of my lack of certainty in my ability to perform the duties of a faculty member. The teaching development area is where it comes across strongest, as I value training engineers who are ready to take the reins and challenge the status quo with creative problem solving." 
Maggie's last quote combines her expectations with a hint of her intrinsic values in a bi-directional manner. On the one hand, her expectations of performance seem to precede the definition of her interest and attainment values. On the other hand, her intrinsic motivation to train future engineers seems to foster her confidence in conveying the image of someone who recognizes what it requires to become a good teacher. As Maggie herself commented, this uncertainty might be related to the strong image she portrayed as a successful student through her undergraduate education and the beginning of graduate school. Advisors and peers alike might have operated under the assumption that she understood more about the academic community than she actually did, which in turn made it more difficult for her to ask for help. Therefore, writing a PDP and discussing it openly with expert guidance was a very valuable experience for her, as it was for all participants in the study. This claim will be supported when looking at the second research question.

\section{Mentoring}

Most participants in this study related how they have had the opportunity to mentor students. Moreover, they are confident in their ability to mentor graduate and undergraduate students, and many of them disclosed an actual interest in engaging in mentoring.

"Other areas, such as mentoring of students, I did not include as I have successfully mentored many undergraduate students.”

Brandon (reflection)

"I have a solid mentorship experience as a graduate student as I have trained multiple undergrads and graduate students in my lab for different research projects. So, I think I would be able to do this well in my job as a faculty member."

Harsh (reflection)

"Next [to teaching and research] is the planning for mentoring graduate students which, in my opinion, is the most fulfilling aspect of the faculty's job."

Hassan (reflection)

Arguably, Hassan is intrinsically motivated towards mentoring and weighs it as important as teaching and research. From the students' perspective, Maggie brought new dimensions to the mentoring function. The following insightful reflection resulted precisely from her being confronted with the task of writing a PDP for her own career:

"While I have received excellent mentoring in research and teaching, I have not had a mentor take interest in my professional development as a whole."

Maggie (reflection)

Interestingly, Paul provided his view of such additional dimensions of mentoring. He not only discussed the type of things he wants to facilitate for his mentees but also expressed his confidence to accomplish them:

"While writing PDP for the first time, I believed I could be a good researcher and mentor. I need to get my students placed in industry or academia, and I think I will fulfil that role with ease. I need to devise a development plan, unique to each of my students, and I think I can do it fine. [...] I will need to create a welcoming and diverse culture for all my students, and I think I will be good at it."

Paul (reflection) 
On the surface, there seems to be no direct link between mentoring and the ideas of balance discussed thus far. However, when discussing teaching, some participants considered the interaction with their students to be stress-relieving, instructive, and gratifying. It is not unreasonable to extend these traits to the mentor-mentee relationship, but further exploration is necessary to portray mentoring as a means to achieve a balanced faculty career.

Research Question 2: The usefulness of writing a PDP with experienced guidance in a formal class

Writing the PDP within the context of the SEP class helped students in at least three distinctive ways. First, some of them had the chance to correct fundamental misconceptions about the faculty job and the faculty functions themselves. Secondly, they gained a more detailed and comprehensive view of the faculty job. Thirdly, they had the chance to reflect systematically on their professional career.

In some cases, the class helped students correct misconceptions directly linked to the idea of balance between teaching and research. For instance, Brandon mentioned during the conversation:

"Early in this class I had the fundamental assumption that the ideas of research and teaching were divided. And, as I walked through this class, I began to more see the holistic nature of scholarship in general and how one feeds into the other. [...] Teaching is a mindset, a way of exploring questions and providing answers in a concrete way, and that mindset can shape how you approach a research question."

Brandon (fishbowl)

The class also helped students expand their perception of the different faculty functions, particularly beyond research and teaching.

"I believed that these [research and teaching] are the evaluation criteria to be a faculty member. I was not entirely sure about the other roles (e.g. mentor, departmental roles, serving committee, etc.) of a faculty member. It was a 'black box' to me. For me, the definition of the faculty member was extremely simple, 'great researcher, good teacher."”

Sayan (reflection)

"Before [the class] I did not have... I did not pay attention to these two aspects [of academic administration and service]. For me the job was research and teaching, and I had experience at both sufficiently, and that's my impression at that time. [...] I completely considered the professor job to be research plus teaching."

Hassan (reflection)

"While writing the PDP for the first time, I was not considering the aspect of several administrative positions that can be held by a professor (e.g., Dean, Provost, etc.). I am now aware of these administrative roles through the [SEP] classes."

Paul (reflection)

Sayan, Hassan, and Paul are arguably better equipped to put together a realistic and effective PDP now that they have a more comprehensive understanding of the faculty job. Similarly, the following quote from Maggie points to the expanded comprehension of faculty functions beyond teaching and research. Moreover, it reveals a critical moment of reflection on her goals and her reasons for wanting to become a faculty member: 
"The professional development plan that I wrote for class was the first time that I enumerated my career and personal development goals." "I believe I had a good understanding of teaching and research responsibilities but a more nebulous idea of mentoring and service." "Nobody had ever sat me down before to figure out where I want to be in the end and how I'm going to get there."

$$
\text { Maggie (reflection + fishbowl) }
$$

This critical opportunity to systematically reflect about their motivation to become faculty members is, possibly, the major takeaway that students can expect from the SEP class and the PDP writing activity.

\section{Discussion}

Based on the results of the study, it is reasonable to posit that the SEP class proved helpful in addressing students' misconceptions or incomplete conceptions of the faculty job and the faculty functions in and of themselves. Moreover, this class provided students with the chance to pause and reflect on their assumptions and motivation to embark on a faculty career. This pause comes at a critical time when graduate students are about to face the challenges of job search and academic work. Nevertheless, some specific actions can be suggested to improve the positive outcomes of the class in light of the results of this study.

Students' reflection on their deficiencies and the motivation to address them is mainly driven by utility and interest values. However, in order to identify such deficiencies, the aspiring faculty need a referent of the skills possessed by competent faculty, especially when utility values are the main driver. In other words, students compare themselves with the image they have of a faculty member to identify gaps in their preparedness, and frequently this image is not complete. A class like SEP should provide students with an image that is comprehensive of the multiple types of positions and the different expectations of balance between teaching, research, and other functions. Consequently, students could set for themselves expectations that are not only more realistic and pragmatic but also better aligned with their interest values.

Most students in this study showed a preference for research over teaching. This can be the result of attending a research-intensive institution and having as role models advisors and mentors who dedicate themselves intensely to research. Moreover, the image of the faculty functions discussed in the preceding paragraph seems to be also a result of students' experience in such an environment. However, the majority of the students also want to devote time to teaching, and they want to teach well. For the different reasons presented in the results section, they believe in balancing their research with substantial teaching. It is, therefore, appropriate to expose them to multiple facets of excellent teaching beyond the delivery of content: course design, evidence-based pedagogical strategies, and so forth. Moreover, an introduction to the scholarship of teaching and learning could spark the educational researcher inside some of them and help them build stronger bridges between teaching and research.

In sum, expectations, assumptions, and notions of balance were present across all students' reflections and discussions of their PDPs. The only relevant theme they did not address consistently, referring to the findings of scholarly literature, was the lack of time to accomplish multiple responsibilities ${ }^{1,3,4}$. A few students discussed avoiding time-consuming tasks with low intrinsic or utility value to allocate time for more rewarding activities. Some even mentioned the need to learn to say "no" when asked to engage in too many activities, even if these were aligned with their interests. Nevertheless, no one discussed the impact on their professional and personal lives of being subjected to multiple responsibilities, although 
this topic was discussed in the SEP class. Arguably, this does not result from students considering the issue irrelevant or overlooking it altogether. Rather, the questions and prompts provided in this study might have influenced their focusing strictly on the academic and professional aspects of the PDP.

\section{Conclusion}

In this study, we explored the stories of engineering graduate students aspiring to faculty positions. In particular, we looked at students' reflections on their PDPs towards preparing for a future faculty career. Existing literature on the experiences of early-career faculty reveals three struggles they usually confront: difficulty in balancing multiple responsibilities, lack of time to cope with them, and unfulfilled expectations. Participants' reflections portrayed ideas of balance between their skills and the expected requirements of the job, balance between teaching and research, and alignment of intrinsic and attainment values with the motivation to become faculty members. Qualitative analysis of these portraits suggests that students must know themselves in order to identify what they have (their strengths), what they need (their deficiencies), and what they want (their expectations and values) to be able to craft effective development plans. However, they also need to contrast their assumptions and expectations with accurate and complete information about the faculty job. By so doing, they can identify deficiencies that are relevant for the path that better suits their values and skills. Therefore, a class like SEP, aimed at helping students prepare to become faculty, should address this challenge from two perspectives. First, students should be provided with enough information about the multiple responsibilities of engineering faculty and the different weights these responsibilities receive across various types of positions and institutions. Secondly, and perhaps more important, the class should provide opportunities for students to reflect on the values underlying their motivation to engage in different faculty functions and, ultimately, become faculty members.

Future work might include the analysis of interviews already conducted with the participants, intended to explore further the content of their reflections and the changes spurred by the SEP class. Moreover, we consider relevant to look deeper into the time limitation theme, particularly from the perspective of the work-life balance idea not addressed explicitly in this study. Finally, we believe that it is possible to conduct a longitudinal study by following-up with the participants within a year or two, once they have more experience in applying for faculty positions or performing the job.

\section{References}

1. Sorcinelli, M. D. New and junior faculty stress: Research and responses. New Dir. Teach. Learn. 2737 (1992).

2. Trower, C. A., Austin, A. E. \& Sorcinelli, M. D. Paradise Lost - How the academy converts enthusiastic recruits into early-career doubters. AAHE Bull. 53, 3-6(2001).

3. Felder, R. \& Brent, R. Helping new faculty get off to a good start. in 5.327.1-5.327.8 (2000).

4. Marra, R. M. \& Litzinger, T. Learning to juggle: A model for new engineering faculty development. in 5.430.1-5.430.12 (2000). 
5. Bruce, L. M. \& Bruce, J. W. Maximizing your productivity as a junior faculty member: Balancing research, teaching, and service. in 9.900.1-9.900.7 (2004).

6. Gaff, J. G. Preparing future faculty and doctoral education. Change Mag. High. Learn. 34, 63-66 (2002).

7. Austin, A. E. et al. Preparing STEM doctoral students for future faculty careers. New Dir. Teach. Learn. 2009, 83-95(2009).

8. Hixson, C., Ingram, E. L., Williams, J. M., Matusovich, H. M. \& McCord, R. E. The rising engineering education faculty experience (REEFE): Preparing junior colleagues. in 26.1569.126.1569.10 (2015).

9. Eccles, J. et al. in Expectancies, values, and academic behaviors (ed. Spence, J. T.) 75-146 (W.H. Freeman, 1983).

10. Matusovich, H. M., Streveler, R. A. \& Miller, R. L. Why do students choose engineering? A qualitative, longitudinal investigation of students' motivational values. J. Eng. Educ. 99, 289-303 (2010).

11. Ortega-Alvarez, J. D., Atiq, S. Z. \& Rodriguez-Simmonds, H. E. A qualitative study investigating how first-year engineering students' value beliefs influence their choice of selecting an engineering major. in 2016 ASEE Annual Conference \& Exposition (2016).

12. Eccles, J. S. in Handbook of competence and motivation (eds. Elliot, A. J. \& Dweck, C. S.) 105-121 (The Guilford Press, 2005).

13. Boud, D. Using journal writing to enhance reflective practice. New Dir. Adult Contin. Educ. 2001,918

14. Kaliya. Unconference methods: fish bowl dialogue. Unconference.net (2006). 